\title{
SISTEM PENDUKUNG KEPUTUSAN PEMILIHAN LOKASI PEMBUKAAN CABANG USAHA ONLINE BICYCLE INDONESIA DENGAN METODE ANALYTICAL HIERARCHY PROCESS (AHP) DAN TECHNIQUE FOR ORDER PREFERENCE BY SIMILARITY TO IDEAL SOLUTION (TOPSIS)
}

\author{
Rizki Adha \\ Program Studi Magister Ilmu Komputer, Program Pascasarjana \\ Universitas Budi Luhur \\ Email: rizkiadha67@gmail.com \\ Tjahjanto \\ Program Studi Magister Ilmu Komputer, Program Pascasarjana \\ Universitas Budi Luhur \\ Email: cahyanto@budiluhur.ac.id
}

\begin{abstract}
ABSTRAK
Pemilihan lokasi usaha akan mempengaruhi risiko dan keuntungan perusahaan tersebut secara keseluruhan. Kondisi ini terjadi karena lokasi sangat mempengaruhi biaya tetap maupun biaya variabel, baik dalam jangka menengah maupun jangka panjang. Lokasi usaha sebaiknya diperhitungkan pada saat perencanaan, sehingga usaha yang akan dijalankan tersebut dapat terorganisir pelaksanaannya di masa mendatang. Online Bicycle Indonesia merupakan startup yang bergerak dibidang jasa pengiriman barang dan makanan dengan menggunakan sepeda berbasis online, akan membuka cabang di beberapa kota dan kabupaten di daerah Tangerang Raya. Agar hasil pemilihan lokasi cabang tepat, diperlukan suatu sistem pendukung keputusan yang dinamis yang nantinya dapat digunakan sebagai pertimbangan manajer dalam proses pemilihan lokasi cabang. Permasalahan dalam pemilihan cabang perusahaan ini dapat digunakan Sistem Pendukung Keputusan (SPK) menggunakan metode AHP-TOPSIS. Metode Analytical Hierarchy Process (AHP) memliki kelebihan berdasar pada matriks perbandingan pasangan dan melakukan analisis konsistensi, sedangkan metode Technique For Order Preference by Similarity to Ideal Solution (TOPSIS) dapat menyelesaikan pengambilan keputusan secara praktis, karena konsepnya sederhana dan mudah dipahami, komputasinya efisien, serta memiliki kemampuan mengukur kinerja relatif dari alternatifalternatif keputusan. Hasil dari penelitian menunjukan Kota Tangerang Selatan lebih unggul dengan bobot 0,824, kedua Kota Tangerang dengan bobot 0,732 dan ketiga Kabupaten Tangerang dengan bobot 0,0. Keputusan yang diambil dapat dipertanggungjawabkan dengan dukungan dari perhitungan yang dilakukan dengan metode AHP-TOPSIS sebagai model dalam sistem pendukung keputusan.
\end{abstract}

Kata kunci: sistem pendukung keputusan (SPK), AHP, TOPSIS, pemilihan lokasi, online bicycle

\section{ABSTRACT}

The choice of business location will affect the risks and benefits of the company as a whole. This condition occurs because the location greatly affects the fixed costs and variable costs, both in the medium term and long term. The location of the business should be taken into account at the time of planning, so that the business to be run can be organized implementation in the future. Online Bicycle Indonesia is a startup engaged in goods and food delivery services by using onlinebased bike, will open branches in several cities and districts in Tangerang Raya area so that the result of choosing the right branch location, required a dynamic decision support system that can later be used as consideration of managers in the process of selecting branch locations. Problems in selecting branch of this company can be used Decision Support System using AHP-TOPSIS method. Analytical Hierarchy Process (AHP) method has advantages based on pair comparison matrix and perform consistency analysis, while Technique For Order Preference by Similarity to 
Ideal Solution (TOPSIS) method can solve practical decision making, because the concept is simple and easy to understand, and have the ability to measure the relative performance of decision alternatives. The results of the study show Kota Tangerang Selatan is superior to the weight of 0.824 , the two Kota Tangerang with a weight of 0.732 and three Kabupaten Tangerang with a weight of 0.0, The decision taken can be accounted for by the calculation of AHP-TOPSIS as a model in the decision support system.

Keywords: decision support system, AHP, TOPSIS, site selection, online bicycle

\section{PENDAHULUAN}

Pemilihan lokasi usaha oleh suatu organisasi (perusahaan) akan mempengaruhi risiko (risk) dan keuntungan (profit) perusahaan tersebut secara keseluruhan. Kondisi ini terjadi karena lokasi sangat mempengaruhi biaya tetap ( $f i x$ cost) maupun biaya variabel (variable cost), baik dalam jangka menengah maupun jangka panjang. Di dalam manajemen organisasi, lokasi usaha sebaiknya diperhitungkan pada saat perencanaan, sehingga usaha yang akan dijalankan tersebut dapat terorganisir pelaksanaannya di masa mendatang (Heizer dan Render, 2004).

Online Bicycle Indonesia merupakan startup yang bergerak dibidang jasa pengiriman barang dan makanan dengan menggunakan sepeda berbasis online, untuk melakukan transaksi dan pemesanan customer dan rider menggunakan aplikasi Online Bicycle yang tersedia untuk Android dan IOS, aplikasi ini merupakan gerakan resolusi bisnis dengan konsep Integrated Green Digital yang mengkonvergensikan antara passion, hobi, bisnis dan idealisme. Fitur unggulan dari aplikasi ini adalah Gowes Send dan Gowes Food. Gowes Send untuk jasa pengiriman barang dan dokumen sedangkan Gowes Food untuk jasa antar makanan.

Pada tahap awal Online Bicycle akan membuka cabang di beberapa kota dan kabupaten di daerah Tangerang Raya. Selain Tangerang sebagai tanah kelahiran Online Bicycle itu sendiri, Tangerang juga merupakan daerah yang sedang berkembang pesat terutama daerah Tangerang Kota dan Tangerang Selatan. Namun sebelum menentukan lokasi cabang tentunya perlu ada riset yang dilakukan. Untuk dapat menentukan lokasi dalam pembukaan cabang ditentukan oleh beberapa faktor. Dengan adanya faktor ini maka tujuan utama dalam menjalankan usaha dapat tercapai. Adapun faktor-faktor tersebut antara lain antara lain potensi lokasi, luas daerah, kepadatan penduduk, pusat kuliner, pusat usaha, bisnis dan kepadatan lalulintas.

Agar hasil pemilihan tempat atau lokasi cabang yang tepat, diperlukan pemilihan lokasi oleh manajer atau pimpinan perusahaan selaku pemegang kendali sebuah usaha. Agar dapat memilih lokasi cabang yang tepat, diperlukan suatu sistem pendukung keputusan yang dinamis yang nantinya dapat digunakan sebagai pertimbangan manajer dalam proses pemilihan lokasi cabang. Permasalahan dalam pemilihan cabang perusahaan ini dapat digunakan sistem pendukung keputusan menggunakan metode AHP-TOPSIS, Dimana metode Analytical Hierarchy Process (AHP) memliki kelebihan berdasar pada matriks perbandingan berpasangan dan melakukan analisis konsistensi. Sedangkan metode Technique for Order Preference by Similarity to Ideal Solution (TOPSIS) dapat menyelesaikan pengambilan keputusan secara praktis, karena konsepnya sederhana dan mudah dipahami, komputasinya efisien, serta memiliki kemampuan mengukur kinerja relatif dari alternatif-alternatif keputusan [1].

Penulis juga melampirkan penelitian terdahulu yang berkaitan dengan penelitian penulis. Penelitian terdahulu sebagai berikut:

1. Penelitian yang dilakukan oleh Sri Winiarti dan Ulfah Yuraida dengan judul "Aplikasi Sistem Pendukung Keputusan penentuan lokasi pendirian Warnet dengan Metode Analytical Hierarchy Process (AHP) (Studi Kasus : PT. Pika Media Komunika)". Masalah pada penelitian ini adalah adanya kesulitan bagi perusahaan dalam menentukan lokasi yang tepat untuk pendirian warnet yang sesuai dengan keinginan perusahaan. Penelitian ini menghasilkan kesimpulan pengujian yang dilakukan terhadap aplikasi sistem pendukung keputusan penentuan lokasi pendirian warnet dapat disimpulkan bahwa sistem yang dibuat membantu manager dalam pengambilan keputusan secara cepat, tepat dan lebih teliti dalam proses penentuan lokasi pendirian warnet [2]. 
2. Penelitian yang dilakukan oleh Jiaqin Yang dan Huei Lee dengan Judul "An AHP decision model for facility location selection" masalah dalam penelitian ini perusahaan mengalami kesulitan dalam menentukan lokasi fasilitas baru atau relokasi fasilitas yang ada. Penelitian ini menghasilkan kesimpulan yang menunjukkan bahwa model AHP dapat menyediakan kerangka kerja untuk membantu pengambil keputusan dalam menganalisis berbagai faktor lokasi, mengevaluasi alternatif lokasi dan membuat pilihan lokasi akhir [3].

3. Penelitian yang dilakukan oleh Ali Al Maliki, Gary Owens dan David Bruce dengan Judul "Combining AHP and TOPSIS Approaches to Support Site Selection for a Lead Pollution Study". Masalah dalam penelitian ini perusahaan akan menentukan lokasi yang paling sesuai untuk melakukan studi pencemaran timbal, studi kasus yang melibatkan evaluasi enam wilayah pertambangan dan peleburan di seluruh Australia, Penelitian ini menghasilkan kesimpulan bahwa menemukan lokasi yang paling sesuai di antara enam alternatif untuk melakukan studi pencemaran timbal berdasarkan kriteria seleksi yang telah ditetapkan, yang menggabungkan dua metode pengambilan keputusan. AHP digunakan untuk menentukan bobot tujuh kriteria, dipilih berdasarkan efek kesehatan manusia, dengan perbandingan pasangan. Selanjutnya, TOPSIS diterapkan untuk mencapai preferensi peringkat akhir dalam urutan menurun sehingga memungkinkan pertunjukan relatif dibandingkan. Dengan menggunakan pendekatan pengambilan keputusan beberapa kriteria ini, Port Pirie diidentifikasi sebagai lokasi terbaik untuk melakukan studi pencemaran timbal. Metode yang digunakan pada penelitian ini adalah AHPTOPSIS [4].

4. Penelitian yang dilakukan oleh Zeljko Stevic, Asib Alihodzic, Zdravko Bozickovic dan Marko Vasiljevic dengan Judul "Application Of Combined AHP-TOPSIS Model For Decision Making In Management". Masalah dalam penelitian ini kesulitan dalam pemilihan perusahaan pengadaan material terbaik. Penelitian ini menghasilkan kesimpulan Untuk mendapatkan solusi optimal, yaitu untuk mendapatkan hasil yang valid yang memberikan solusi masalah spesifik, khususnya dalam hal pemilihan perusahaan untuk pengadaan, perlu untuk memenuhi dan mengikuti langkahlangkah spesifik dalam analisis multi kriteria. Setelah semua langkah yang dilakukan rinci dalam makalah ini, telah disimpulkan bahwa peringkat akhir alternatif adalah yang diberikan pada gambar sebelumnya, yang menunjukkan bahwa dua alternatif, yaitu perusahaan Trigometal merupakan solusi terbaik untuk pengadaan material. Perlu dicatat bahwa tidak mungkin membuat keputusan strategis dan operasional yang secara bersamaan mencakup kriteria yang berbeda tanpa teknik analisis multi kriteria, yang selanjutnya menekankan pentingnya penelitian ini, di mana pemilihan pengadaan material yang optimal untuk perusahaan yang diamati telah dilakukan. Berdasarkan hal tersebut di atas, dapat disimpulkan bahwa penerapan metode analisis multi kriteria menghasilkan hasil optimal yang berlaku dalam praktik. Metode yang digunakan pada penelitian ini adalah AHP-TOPSIS [5].

\section{METODOLOGI PENELITIAN}

Pada sistem yang dirancang ini menggunakan basis model yang diambil dari penggabungan antara model AHP dan model TOPSIS. Pada tahap tersebut model yang pertama kali digunakan adalah model AHP (menentukan matrik keputusan yang menunjukan skor setiap alternatif pada semua kriteria) kemudian dilanjutkan dengan metode TOPSIS untuk menentukan perankingan tiap alternatif. Adapun tahap analisa tersebut dapat digambarkan ke dalam flowchart. 


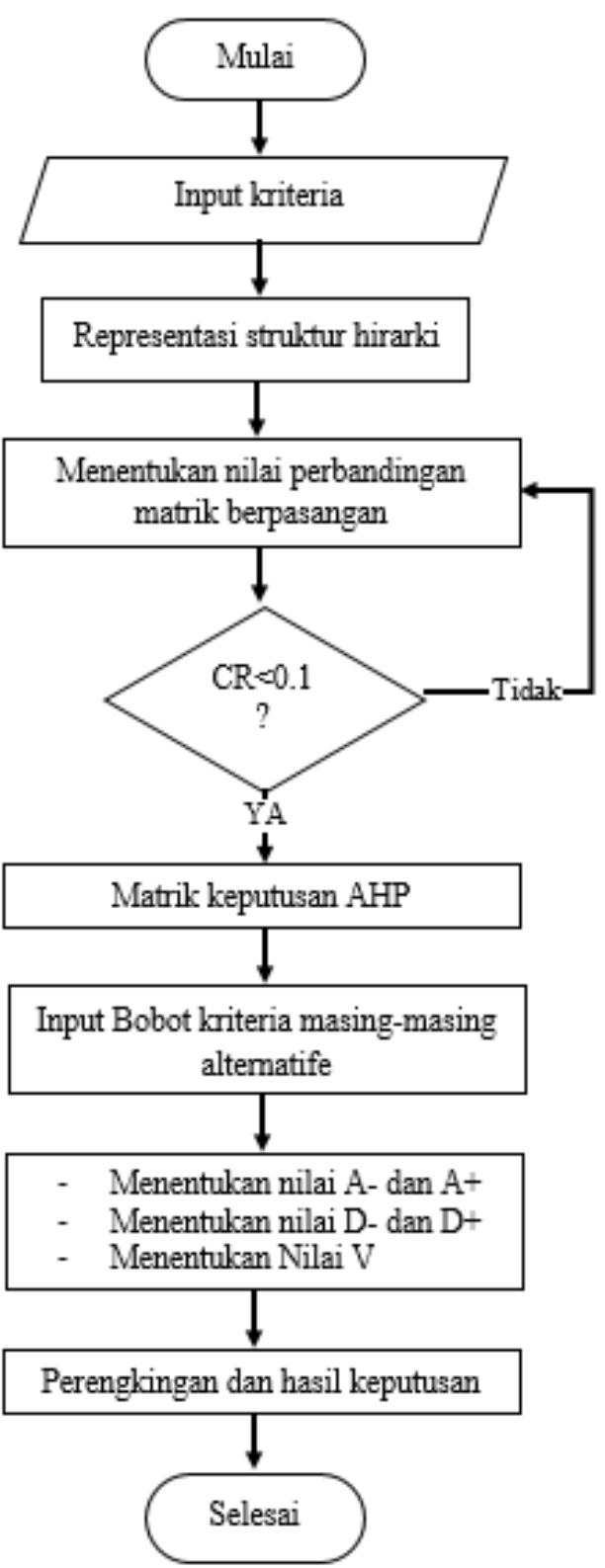

\section{HASIL DAN PEMBAHASAN}

\section{Gambar 1. Flowchart Analisa Model AHP-TOPSIS}

\subsection{Metode $\mathrm{AHP}$}

\subsubsection{Hirarki dan Tingkat Kepentingan}

Berikut adalah struktur hirarki sistem pendukung keputusan pemilihan lokasi cabang usaha dipaparkan pada Gambar 4.1. 


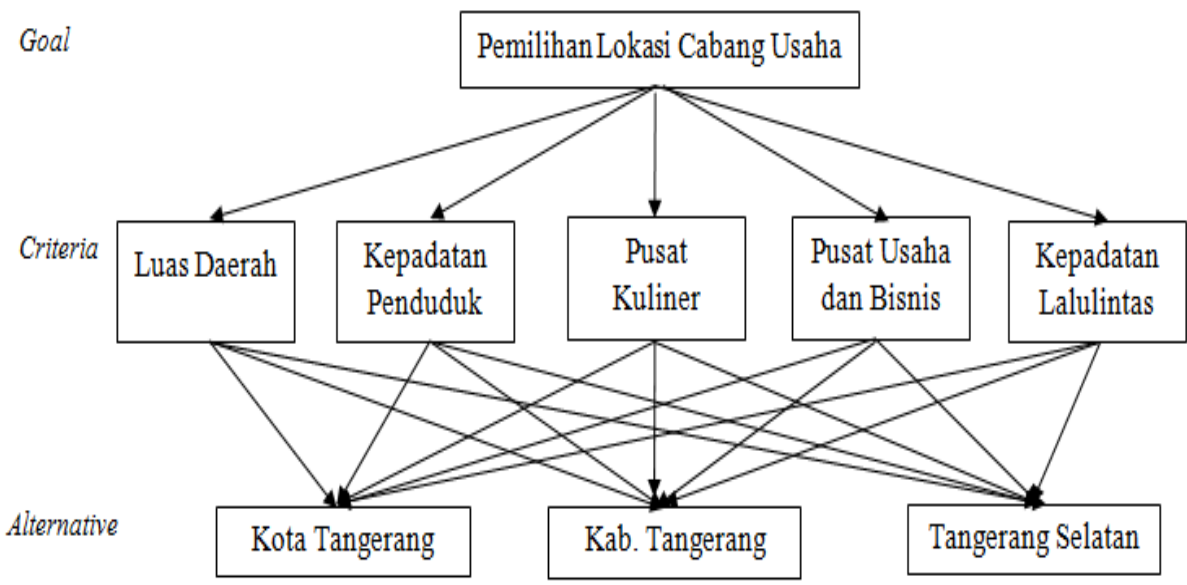

Gambar 2. Struktur Hierarki

\subsubsection{Tahap Pembobotan Kriteria dengan Metode AHP}

Berikut merupakan pembobotan terhadap kriteria-kriteri yang mempengaruhi pemilihan lokasi pembukaan cabang usaha online bicycle sesuai dengan kebutuhan perusahaan.

Tabel 1. Hasil Pembobotan Kriteria dengan Metode AHP

\begin{tabular}{|c|c|c|c|c|c|}
\hline $\begin{array}{r}\mathrm{K} \\
\text { riteria }\end{array}$ & $\mathrm{C} 1$ & $\mathrm{C} 2$ & $\mathrm{C} 3$ & $\mathrm{C} 4$ & $\mathrm{C} 5$ \\
\hline $\mathrm{C} 1$ & 1,00 & 0,33 & 0,17 & 0,20 & 1,00 \\
\hline $\mathrm{C} 2$ & 3,00 & 1,00 & 0,33 & 0,50 & 3,00 \\
\hline $\mathrm{C} 3$ & 6,00 & 3,00 & 1,00 & 2,00 & 6,00 \\
\hline $\mathrm{C} 4$ & 5,00 & 2,00 & 0,50 & 1,00 & 5,00 \\
\hline $\mathrm{C} 5$ & 1,00 & 0,33 & 0,17 & 0,20 & 1,00 \\
\hline Jumlah & 16,00 & 6,67 & 2,17 & 3,90 & 16,00 \\
\hline
\end{tabular}

Keterangan tabel:
C1 : Luas Daerah
C2 : Kepadatan Penduduk
C3 : Pusat kuliner
C4 : Pusat usaha
C5 : Kepadatan Lalulintas

Dari matriks perbandingan diatas, maka dapat dihitung nilai eigen, lamda maksimum, dan CR. Sebelum menghitung nilai eigen, dicari nilai perbandingan pada tiap kolom dibagi dengan jumlah kolomnya, seperti di bawah ini.
$\mathrm{C} 1=1 / 16,00 \quad=0.06$
$\mathrm{C} 2=0,33 / 6,67=0.05$
$\mathrm{C} 3=0,17 / 2,17=0.08$
$\mathrm{C} 4=0,20 / 3,90=0.05$
$\mathrm{C} 5=1 / 16,00 \quad=0.06$

dan seterusnya untuk kolom ke-2

Tabel 2. Nilai Perbandingan Tiap Kolom Dibagi Jumlah Kolom 


\begin{tabular}{|c|c|c|c|c|c|}
\hline Kriteria & C1 & C2 & C3 & C4 & C5 \\
\hline C1 & 0,063 & 0,050 & 0,077 & 0,051 & 0,063 \\
\hline C2 & 0,188 & 0,150 & 0,154 & 0,128 & 0,188 \\
\hline C3 & 0,375 & 0,450 & 0,462 & 0,513 & 0,375 \\
\hline C4 & 0,313 & 0,300 & 0,231 & 0,256 & 0,313 \\
\hline C5 & 0,063 & 0,050 & 0,077 & 0,051 & 0,063 \\
\hline Jumlah & 1 & 1 & 1 & 1 & 1 \\
\hline
\end{tabular}

Setelah diperoleh hasil pembagian tiap kolomnya, maka dapat dihitung nilai eigen dengan persamaan rumus (2.1) yaitu dengan menjumlahkan nilai-nilai dari setiap baris dan membaginya dengan banyak elemen kriteria untuk mendapatkan rata-rata. Seperti nilai eigen untuk baris kriteria pertama dan kedua (C1dan $\mathrm{C} 2$ ) dan hasil penjumlahan nilai eigen akan selalu bernilai satu.

Eigen untuk kriteria $\mathrm{C} 1$

$\mathrm{C} 1=\frac{0,063+0,050+0,077+0,051+0,063}{5}=0,061$

Eigen untuk kriteria $\mathrm{C} 2$

$\mathrm{C} 2=\frac{0,188+0,150+0,154+0,128+0,188}{5}=0,161$

Kriteria selanjutnya, disajikan pada Table 3.3

Tabel 3. Nilai Eigen

\begin{tabular}{|c|c|c|c|c|c|l|}
\hline Kriteria & $\mathrm{C} 1$ & $\mathrm{C} 2$ & $\mathrm{C} 3$ & $\mathrm{C} 4$ & $\mathrm{C} 5$ & Eigen \\
\hline $\mathrm{C} 1$ & 0,063 & 0,050 & 0,077 & 0,051 & 0,063 & 0,061 \\
\hline $\mathrm{C} 2$ & 0,188 & 0,150 & 0,154 & 0,128 & 0,188 & 0,161 \\
\hline $\mathrm{C} 3$ & 0,375 & 0,450 & 0,462 & 0,513 & 0,375 & 0,435 \\
\hline $\mathrm{C} 4$ & 0,313 & 0,300 & 0,231 & 0,256 & 0,313 & 0,282 \\
\hline C5 & 0,063 & 0,050 & 0,077 & 0,051 & 0,063 & 0,061 \\
\hline Jumlah & 1 & 1 & 1 & 1 & 1 & 1 \\
\hline
\end{tabular}

Selanjutnya Menentukan nilai CI (Consistency Index) dengan persamaan:

$\mathbf{C I}=\frac{\lambda_{\max }-\mathbf{n}}{\mathrm{n}-1} \quad \lambda$ maksimum $=\left(\sum \mathrm{GM}_{11^{-} \mathrm{n} 1} \times \ddot{\mathrm{X}} 1\right)+\ldots+\left(\sum \mathrm{GM}_{11^{-} \mathrm{n} 1} \times \ddot{\mathrm{X}} 1\right)$

Keterangan :

$\mathrm{n}=$ Banyaknya Elemen

Sehingga didapatkan hasil sebagai berikut.

$\lambda$ maksimum $=5,04$

$\mathrm{CI}=\frac{5,04-5}{5-1}$

$=0,01$

\subsubsection{Uji Batas Ketidak Konsistenan yang Diterapkan oleh Saaty}

Pengujian diukur menggunakan nilai CR (Consistency Ratio), yaitu perbandingan antara nilai CI dan RI, dimana nilai RI (Random Index) dapat dilihat pada tabel Random Index yang telah 
dijelaskan pada bab sebelumnya. Apabila nilai CR lebih kecil dari $10 \%(0,1)$ maka ketidak konsistenan pendapat masih dapat diterima.

Sehingga didapatkan nilai CR yaitu :

$$
\begin{aligned}
\mathrm{CR} & =\frac{0,01}{1,12} \\
& =0,009
\end{aligned}
$$

Hasil CR $<0.1$ maka dinyatakan konsisten dan dapat diterima.

\subsection{Metode TOPSIS}

\subsubsection{Tahap Perangkingan dengan Metode TOPSIS}

Langkah selanjutnya setelah mendapatkan hasil perankingan dari metode AHP akan melanjutkan tahap perankingan dengan metode TOPSIS, dengan memakai data-data yang sudah dikumpulkan menurut pendapat para ahli.

1. Menyusun Tabel Data Alternatif

Tabel 4. Data Penilaian Alternatif

\begin{tabular}{|c|c|c|c|c|c|}
\hline $\begin{array}{c}\text { Cost/ } \\
\text { Benefit }\end{array}$ & C & B & B & B & B \\
\hline Daerah & C1 & C2 & C3 & C4 & C $_{5}$ \\
\hline $\mathrm{V}_{1}$ & 969,5 & 3587 & 6,5 & 6 & 6,5 \\
\hline $\mathrm{V}_{2}$ & 164,6 & 12724 & 8 & 9 & 9,5 \\
\hline $\mathrm{V}_{3}$ & 147,2 & 10828 & 9,5 & 8 & 8 \\
\hline
\end{tabular}

2. Menghitung Matriks Normalisasi

Nilai matriks ternormalisasi diambil dari data penilaian kriteria masing-alternatif dan diproses menggunakan rumus sebagai berikut.

$\mathrm{r}_{\mathrm{ij}}=\frac{X_{i j}}{\sqrt{\sum_{i=1}^{m} X_{i j}}}$

$\left|X_{l}\right|:$ Dimana : $\mathrm{i}=1,2 \ldots ., \mathrm{n} ;$ dan $\mathrm{j}=1,2, \ldots ., \mathrm{n}$

$\left|X_{1}\right|=\sqrt{(969,5)^{2}+(164,6)^{2}+(147,2)^{2}}$

$=994,3$

$\mathrm{R}_{11}=969,5: 994,3=0,975$

$\mathrm{R}_{12}=164,6: 994,3=0,166$

$\mathrm{R}_{13}=147,2: 994,3=0,148$

$\left|X_{2}\right|=\sqrt{(3587)^{2}+(12724)^{2}+(10828)^{2}}$

$=17088,4$

$\mathrm{R}_{11}=3587: 17088,4=0,210$

$\mathrm{R}_{12}=12724: 17088,4=0,745$

$\mathrm{R}_{13}=10828: 17088,4=0,634$

Selanjutnya lihat Tabel 5 
Tabel .5 Nilai Normalisasi

\begin{tabular}{|c|c|c|c|c|c|}
\hline Daerah & $\mathrm{C}_{1}$ & $\mathrm{C}_{2}$ & $\mathrm{C}_{3}$ & $\mathrm{C}_{4}$ & $\mathrm{C}_{5}$ \\
\hline Pembagi & 994,3 & 17088,4 & 14,0 & 13,5 & 14,0 \\
\hline $\mathrm{V}_{1}$ & 0,975 & 0,210 & 0,464 & 0,446 & 0,464 \\
\hline $\mathrm{V}_{2}$ & 0,166 & 0,745 & 0,571 & 0,669 & 0,678 \\
\hline $\mathrm{V}_{3}$ & 0,148 & 0,634 & 0,678 & 0,595 & 0,571 \\
\hline
\end{tabular}

3. Menghitung Matriks Normalisasi Terbobot

Langkah selanjutnya adalah menentukan nilai matriks ternormalisasi terbobot dengan cara mengalikan setiap elemen dengan bobot kriteria masing-masing yang telah didapat dari perhitungan menggunakan metode AHP seperti yang telah dijelaskan sebelumnya dengan rumus sebagai berikut.

$\mathrm{y}_{\mathrm{ij}}=\mathrm{w}_{\mathrm{i}} * \mathrm{r}_{\mathrm{ij}}$ dengan $\mathrm{i}=1,2, \ldots, \mathrm{n}$; dan $\mathrm{j}=1,2, \ldots, \mathrm{n}$

$\mathrm{y}_{11}=(0,061)(0,975)=0,059$

$\mathrm{y}_{12}=(0,161)(0,210)=0,034$

$\mathrm{y}_{13}=(0,435)(0,424)=0,185$

$\mathrm{y}_{14}=(0,282)(0,416)=0,117$

$\mathrm{y}_{15}=(0,061)(0,424)=0,026$

Selanjutnya lihat Tabel 6

Tabel 6. Normalisasi Terbobot

\begin{tabular}{|c|c|c|c|c|c|}
\hline $\mathrm{V}$ & $\mathrm{C}_{1}$ & $\mathrm{C}_{2}$ & $\mathrm{C}_{3}$ & $\mathrm{C}_{4}$ & $\mathrm{C}_{5}$ \\
\hline $\mathrm{V}_{1}$ & 0,059 & 0,034 & 0,185 & 0,117 & 0,026 \\
\hline $\mathrm{V}_{2}$ & 0,010 & 0,120 & 0,246 & 0,196 & 0,043 \\
\hline $\mathrm{V}_{3}$ & 0,009 & 0,102 & 0,308 & 0,166 & 0,034 \\
\hline
\end{tabular}

4. Mengidentifikasi Solusi Ideal Positif dan Solusi Ideal Negatif

Solusi ideal positif $(\mathrm{A}+)$ diperoleh dengan mencari nilai maksimal dari nilai normalisasi terbobot jika atributnya adalah atribut keuntungan (benefit) dan mencari nilai minimal dari nilai normalisasi terbobot jika atributnya adalah atribut biaya (cost).

Solusi ideal negatif (A-) diperoleh dengan mencari nilai minimal dari nilai normalisasi terbobot jika atributnya adalah atribut keuntungan (benefit) dan menjadi nilai maksimal dari nilai normalisasi terbobot jika atributnya adalah atribut keuntungan (benefit) dan menjadi nilai maksimal dari nilai normalisasi terbobot jika atributnya adalah atribut biaya (cost).

Menentukan Solusi Ideal Positif (A+) dan Matriks Ideal Negatif (A-).

Rumus:

a. Atribut benefit $=\mathrm{A}+=\operatorname{Max}\left(\mathrm{y}_{1}, \mathrm{y}_{2}, \ldots, \mathrm{y}_{\mathrm{n}}\right)$ dan $\mathrm{A}-=\operatorname{Min}\left(\mathrm{y}_{1}, \mathrm{y}_{2}, \ldots, \mathrm{y}_{\mathrm{n}}\right)$

b. Atribut cost $=\mathrm{A}+=\operatorname{Min}\left(\mathrm{y}_{1}, \mathrm{y}_{2}, \ldots, \mathrm{y}_{\mathrm{n}}\right)$ dan $\mathrm{A}-=\operatorname{Max}\left(\mathrm{y}_{1}, \mathrm{y}_{2}, \ldots, \mathrm{y}_{\mathrm{n}}\right)$

Tabel 7. Nilai Solusi Ideal Positif dan Solusi Ideal Negatif

\begin{tabular}{|c|c|c|c|c|c|}
\hline $\begin{array}{c}\text { Cost/ } \\
\text { Benefit }\end{array}$ & C & B & B & B & B \\
\hline & $\mathrm{C}_{1}$ & $\mathrm{C}_{2}$ & $\mathrm{C}_{3}$ & $\mathrm{C}_{4}$ & $\mathrm{C}_{5}$ \\
\hline $\mathrm{A}+$ & 0,009 & 0,120 & 0,295 & 0,189 & 0,041 \\
\hline $\mathrm{A}-$ & 0,059 & 0,034 & 0,202 & 0,126 & 0,028 \\
\hline
\end{tabular}

5. Menghitung Jarak Antara Nilai Setiap Alternatif dengan Matriks Solusi Ideal Positif dan Matriks Solusi Ideal Negatif. 
Jarak antara alternatif dengan solusi ideal positif digunakan rumus:

$$
D_{i}=\sqrt{\sum_{i=1}^{n}\left(y_{t}-y_{t_{i}}\right)^{2}}
$$

Sedangkan jarak antara alternatif dengan solusi ideal negatif digunakan rumus:

$$
\begin{aligned}
& \quad D_{i}^{-}=\sqrt{\sum_{i=1}^{n}\left(y_{i j}-y_{i}^{-}\right)^{2}} \\
& =\sqrt{\left((0,009-0,059)^{\wedge} 2+(0,120-0,034)^{\wedge} 2+(0,295-\right.} \\
& \left.0,202)^{\wedge} 2+(0,189-0,126)^{\wedge} 2+(0,041-0,028)^{\wedge} 2\right) \\
& =0,151 \\
& D_{2}{ }^{+}=\sqrt{\left((0,009-0,010)^{\wedge} 2+(0,120-0,120)^{\wedge} 2+(0,295-\right.} \\
& \left.0,248)^{\wedge} 2+(0,189-0,189)^{\wedge} 2+(0,041-0,041)^{\wedge} 2\right) \\
& =0,047 \\
& D_{a}{ }^{+}=\sqrt{ }\left((0,009-0,009)^{\wedge} 2+(0,120-0,102)^{\wedge} 2+(0,295-\right. \\
& \left.0,295)^{\wedge} 2+(0,189-0,168)^{\wedge} 2+(0,041-0,035)^{\wedge} 2\right) \\
& =0,028 \\
& D_{1}^{-}=\sqrt{\left((0,059-0,059)^{\wedge} 2+(0,034-0,034)^{\wedge} 2+(0,202-\right.} \\
& \left.0,202)^{\wedge} 2+(0,126-0,126)^{\wedge} 2+(0,028-0,028)^{\wedge} 2\right) \\
& =0,000 \\
& D_{2}^{-}=\sqrt{\left((0,059-0,010)^{\wedge} 2+(0,034-0,120)^{\wedge} 2+(0,202-\right.} \\
& \left.0,248)^{\wedge} 2+(0,126-0,189)^{\wedge} 2+(0,028-0,041)^{\wedge} 2\right) \\
& =0,127 \\
& D_{a}^{-}=\sqrt{\left((0,059-0,009)^{\wedge} 2+(0,034-0,102)^{\wedge} 2+(0,202-\right.} \\
& \left.0,295)^{\wedge} 2+(0,126-0,168)^{\wedge} 2+(0,028-0,035)^{\wedge} 2\right) \\
& =0,133
\end{aligned}
$$

Tabel 8. Nilai Jarak Ideal Positif dan Jarak Ideal Negatif

\begin{tabular}{|c|c|c|}
\hline Alternatif & $\mathrm{D}_{+}$ & $\mathrm{D}_{-}$ \\
\hline $\mathrm{V}_{1}$ & 0,151 & 0,000 \\
\hline $\mathrm{V}_{2}$ & 0,047 & 0,127 \\
\hline $\mathrm{V}_{3}$ & 0,028 & 0,133 \\
\hline
\end{tabular}

6. Menentukan Nilai Kedekatan Setiap Alternatif Terhadap Solusi Ideal (nilai preferensi) Nilai Preferensi (V) untuk setiap alternatif digunakan rumus:

$$
\begin{aligned}
& \mathrm{V}_{\mathrm{i}}=\quad \mathrm{D}_{\mathrm{i}}^{-} / \mathrm{D}_{\mathrm{i}}^{-}+\mathrm{D}_{\mathrm{i}}^{+} \quad \text { dengan } \mathrm{i}=1,2, \ldots, \mathrm{n} \\
& \mathrm{V}_{1}=0,151 /(0,000+0,151)=0,000 \\
& \mathrm{~V}_{1}=0,047 /(0,127+0,047)=0,732
\end{aligned}
$$




$$
\mathrm{V}_{1}=0,028 /(0,133+0,028)=0,824
$$

Tabel 9. Alternatif Ranking

\begin{tabular}{|l|c|c|}
\hline \multicolumn{1}{|c|}{ Alternatif } & Total & Rank \\
\hline Kab. Tangerang & 0,000 & 3 \\
\hline Kota Tangerang & 0,732 & 2 \\
\hline $\begin{array}{l}\text { Kota Tangerang } \\
\text { Selatan }\end{array}$ & 0,824 & 1 \\
\hline
\end{tabular}

\section{KESIMPULAN}

Berdasarkan hasil penelitian, dapat diambil kesimpulan sebagai berikut:

1. Sistem Pendukung Keputusan Pemilihan Lokasi Pembukaan Cabang Usaha Dengan Metode AHP-TOPSIS studi kasus Online Bicycle Indonesia. Bisa dijadikan dasar pengambilan keputusan manajemen dalam proses pemilihan lokasi pembukaan cabang usaha. Adapun hasil dari penelitian menunjukan ranking pertama adalah Kota Tangerang Selatan dengan bobot 0,824, kedua Kota Tangerang dengan bobot 0,732 dan ketiga Kabupaten Tangerang dengan bobot 0,0 . Keputusan yang diambil dapat dipertanggungjawabkan dengan dukungan dari perhitungan yang dilakukan dengan metode AHP-TOPSIS sebagai model dalam sistem pendukung keputusan.

2. Kriteria-kriteria yang telah dianalisa penulis sudah tepat dan mampu membantu dalam pengambilan keputusan dalam mengevaluasi alternatif lokasi dan membuat pilihan lokasi cabang usaha sesuai yang diharapkan pengambil keputusan, dan telah diuji dengan pengujian UAT (User Acceptence Test).

Dari kesimpulan yang telah disebutkan diatas, penulis memberi saran untuk pengembangan lebih lanjut dari Sistem Pendukung Keputusan Pemilihan Lokasi Pembukaan Cabang Usaha Online Bicycle Indonesia Dengan Metode AHP dan TOPSIS yaitu:

1. Untuk menjadikan sistem pendukung keputusan pemilihan lokasi pembukaan cabang usaha Online Bicycle Indonesia menjadi lebih baik dalam tahap implementasi perlu dukungan dari semua pihak baik dari pimpinan sampai kepada user yang menggunakan sistem ini.

2. Sumber daya yang menggunakan sistem menjadi hal penting sehingga perlu di adakan pelatihan yang lebih untuk meningkatkan pemahaman dalam menggunakan sistem tersebut.

Dari segi infrastruktur perlu dipersiapkan dengan semaksimal mungkin, untuk mendapatkan hasil yang maksimal dalam implementasi sistem pendukung keputusan pemilihan lokasi pembukaan cabang usaha.

\section{UCAPAN TERIMA KASIH}

Penulis menyampaikan terima kasih yang tulus kepada: Ibu dan istri tercinta yang senantiasa memberi kasih sayang, nasehat, dorongan semangat yang tiada tara, serta doa yang tidak pernah berhenti mengalir, Bapak Prof. Dr. Sc. Agr. Ir. Didik Sulistyanto, selaku Rektor Universitas Budi Luhur, Bapak Dr. Suhartono, MA., MBA, selaku Ketua Program Pascasarjana Universitas Budi Luhur, Bapak Dr. M. Syafrullah, M.Kom, M.Sc, selaku ketua Program Studi Magister Ilmu Komputer Universitas Budi Luhur, Bapak Dr. Tjahjanto, S.Kom, M.M, selaku pembimbing yang telah banyak memberikan bimbingan dan arahan.. 


\section{DAFTAR PUSTAKA}

[1] Julianti, dkk. Pemilihan Guru Berprestasi Menggunkan Metode AHP dan TOPSIS. Matematika: Universitas Negri Yogyakarta. 2011.

[2] Winiarti, S., \& Yuraida, U. (2009). Aplikasi Sistem Pendukung Keputusan Penentuan Lokasi Pendirian Warnet Dengan Metode Analytical Hierarchy Process (AHP)(Studi Kasus: PT. Pika Media Komunika). Jurnal Informatika, 3(2), 311-322.

[3] Yang, J., \& Lee, H. (1997). An AHP decision model for facility location selection. Facilities.

[4] Al Maliki, A., Owen, G., \& Bruce, D. (2012). Combining AHP and TOPSIS approaches to support site selection for a lead pollution study (Doctoral dissertation, IACSIT Press).

[5] Stević, Ž., Alihodžić, A., Božičković, Z., Vasiljević, M., \& Vasiljević, Đ. (2015). Application of combined AHP-TOPSIS model for decision making in management. In 5th International conference „Economics and Management-based On New Technologies "EMONT/Vrnjačka Banja, Serbia (pp. 33-40). 